\title{
Coulisses
}

Revue de théâtre

25| Hiver 2002

Varia

\section{Le T.U.F.C. et A. Gatti : la traversée des langages : juin 2000-décembre 2002}

\section{Lucile Garbagnati}

\section{(2) OpenEdition}

1 Journals

Édition électronique

URL : http://journals.openedition.org/coulisses/6126

DOI : $10.4000 /$ coulisses. 6126

ISSN : 2546-9460

Éditeur

Presses universitaires de Franche-Comté

\section{Édition imprimée}

Date de publication : 1 janvier 2002

Pagination : 127

ISBN : 2-84627-052-X

ISSN : $1150-594 X$

\section{Référence électronique}

Lucile Garbagnati, «Le T.U.F.C. et A. Gatti : la traversée des langages : juin 2000-décembre 2002 », Coulisses [En ligne], 25 | Hiver 2002, mis en ligne le 24 octobre 2019, consulté le 15 novembre 2019 URL : http://journals.openedition.org/coulisses/6126; DOI : 10.4000/coulisses.6126

Ce document a été généré automatiquement le 15 novembre 2019.

Coulisses 


\title{
Le T.U.F.C. et A. Gatti : la traversée des langages : juin 2000-décembre 2002
}

\author{
Lucile Garbagnati
}

1 Depuis le colloque Temps scientifique temps théâtral en juin 2000, (publié au C.R.D.D.P. de Franche-Comté, 2001 avec le label Arts et Culture), au cours duquel A. Gatti a lu en première mondiale sa pièce : Incertitudes de la mécanique quantique devenant chant des oiseaux du Graal pour l'entrée des groupes (de Galois) dans le langage dramatique des relations suivies se sont établies entre le Théâtre Universitaire de Franche-Comté et La Parole Errante, structure d'A. Gatti. Elles se concrétisent par un projet à plusieurs volets : recherche, publication, cycle de conférences et résidence-création du poète en juin, juillet août 2002 à Besançon, sur le campus de La Bouloie. La pièce est spécialement écrite pour la trentaine d'étudiants de théâtres universitaires

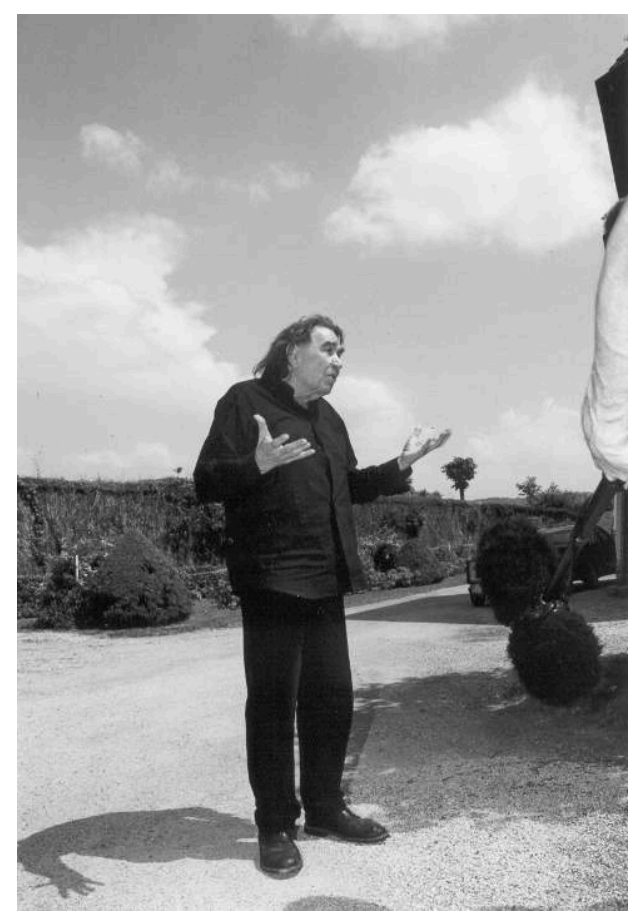
français et francophones. Elles manifestent ainsi une volonté commune de «traverser les langages » pour reprendre l'expression de Gatti. 